\title{
Review Article \\ Targeting Oncogene-Induced Autophagy: A New Approach in Cancer Therapy?
}

\author{
Fuquan Zhang and Jit Kong Cheong \\ Cancer and Stem Cell Biology Program, Duke-NUS Graduate Medical School, 8 College Road, Singapore 169857 \\ Correspondence should be addressed to Jit Kong Cheong; jitkong.cheong@duke-nus.edu.sg
}

Received 31 March 2013; Revised 31 May 2013; Accepted 31 May 2013

Academic Editor: Shi-Yong Sun

Copyright ( 2013 F. Zhang and J. K. Cheong. This is an open access article distributed under the Creative Commons Attribution License, which permits unrestricted use, distribution, and reproduction in any medium, provided the original work is properly cited.

\begin{abstract}
Autophagy is a tightly controlled self-degradation process utilised by cells to sustain cellular homeostasis and to support cell survival in response to metabolic stress and starvation. Thus, autophagy plays a critical role in promoting cell integrity and maintaining proper function of cellular processes. Defects in autophagy, however, can have drastic implications in human health and diseases, including cancer. Described as a double-edged sword in the context of cancer, autophagy can act as both suppressor and facilitator of tumorigenesis. As such, defining the precise role of autophagy in a multistep event like cancer progression can be complex. Recent findings have implicated a role for components of the autophagy pathway in oncogene-mediated cell transformation, tumour growth, and survival. Notably, aggressive cancers driven by Ras oncoproteins rely on autophagy to sustain a reprogrammed mitochondrial metabolic signature and evade cell death. In this review, we summarize our current understanding of the role of oncogene-induced autophagy in cancer progression and discuss how modulators of autophagic responses can bring about therapeutic benefit and eradication of a subset of cancers that are addicted to this ancient recycling machinery.
\end{abstract}

\section{Introduction}

Almost two decades ago, the Ohsumi laboratory first discovered and characterized the autophagy-related $(A T G)$ genes in yeast $[1,2]$. Since then, researchers around the world work relentlessly to unravel the biology of autophagy and its roles in a variety of human diseases.

Autophagy can be broadly categorized into macroautophagy, microautophagy, and chaperone-mediated autophagy. Macroautophagy (hereafter autophagy) is a tightly regulated catabolic mechanism in the cell. It involves the sequestration of dysfunctional cytoplasmic constituents, ranging from misfolded proteins, proteoglycans and damaged organelles into double membrane vesicles, known as the autophagosomes. These autophagic vesicles eventually fuse with lysosomes, within which the dysfunctional cytoplasmic cargoes are degraded. This self-cannibalisation process in the cell appears to play a crucial role in supporting the bioenergetics and biosynthetic programs in response to nutrient deprivation and metabolic duress [3].

Under optimal growth conditions of a normal cell, the autophagic activity is kept in a minimal or basal state. Such basal autophagy is important for maintaining intracellular protein homeostasis and preservation of cellular integrity, through effective clearance of protein aggregates and damaged organelles. Under physiologic stress like starvation, hypoxia, and oncogene activation, this autophagic activity can be upregulated to provide efficient nutrient recycling for damage mitigation, stress tolerance, and sustain shortterm viability of the cell. Given that autophagy-mediated management of energy homeostasis and nutrient recycling are important to the well-being of a cell, it is not surprising that a defective autophagic recycling chain results in human diseases, such as cancer, neurological disorders, and hepatic malfunction $[4,5]$.

Of particular interest to us is the emerging role of basal autophagy as a result of oncogene activation during cancer progression. Due to an increasing number of evidence demonstrating that autophagy can be both pro-tumorigenic and tumor suppressive in cells undergoing the different phases of an oncogene-induced transformation [6,7], oncogeneinduced autophagy is perceived as a "double-edged sword" [8]. As such, it remains an open question whether one should promote or inhibit autophagy to improve the efficacy 
of our existing anticancer regimens. We herein summarize recent experimental findings in the area of oncogene-induced autophagy and speculate how they can help us to devise new diagnostic tools for early cancer detection as well as to develop novel anticancer therapeutics.

\section{Role of Autophagy in Ras-Driven Cancers}

The Ras oncoproteins are members of a large superfamily of guanosine- 5 ' -triphosphate- (GTP-) binding proteins important in controlling activities of signaling pathways regulating normal cellular proliferation [9]. Three closely related Ras oncoproteins have been known so far: H-ras, K-ras, and Nras. In $20-25 \%$ of all human tumors and up to $90 \%$ in specific tumor types, activating mutations in different $R A S$ oncogene members have been reported [10].

\subsection{How Does Oncogenic Ras Modulate Basal Autophagy of the} Cell? A number of reports have shown that the activation of oncogenic Ras alone can promote both tumorigenesis and cell death, which are associated with features of autophagy [1115]. For instance, Ras-induced autophagy can induce cancer cell death via the upregulation of $\mathrm{BH} 3$-only protein Noxa and a key regulator of autophagy, Beclin-1 [15], and yet it is indispensable for tumorigenesis [11-14]. As such, how does one resolve this discrepancy in survival outcomes conferred by oncogenic Ras overexpression and/or activation? It has been argued that varying intensities of Ras activation can lead to different cellular survival outcomes. If acute overexpression/activation of Ras occurs in the absence of cooperating mutations, cells may undergo cellular senescence or autophagic death via Beclin-1/Vps34 lipid kinase activation complex. In the case of chronic overexpression/activation of Ras, cells may be capable of overcoming the initial phase of oncogene activation stress by undergoing growth selection pressure through a "bottle-neck" effect to create favorable mutations for development into a cancerous state [16]. Chronic overexpression/activation of Ras in the cell may, via a weaker activation of its PI3K/Akt/mTOR effector pathway, limit the scale of basal autophagy elevation to favor cell survival over death. This elevated level of basal autophagy was observed in Ras-driven cells from multiple organ/tissue origins [11-14], suggesting that the matter of life and death in the cell may be determined by the "strength/dose" of Ras overexpression/activation rather than differences in cell type/origin.

Intriguingly, it was recently reported that active cross talk between different cellular responses induced by oncogenic Ras exists [17]. Briefly, cellular senescence, not autophagy, was shown to be a dominant outcome of mouse embryonic fibroblasts (MEFs) stably overexpressing oncogenic Ras. This bias towards Ras-induced senescence is mediated by $\mathrm{N}$ terminal apoptosis-stimulating of p53 protein 2 (ASPP2). ASPP2, by competing with ATG16 for binding to the ATG5ATG12 complex, prevents the formation of ATG16-ATG5ATG12 ternary complex for autophagy initiation. Remarkably, overexpression of ATG5 but not autophagy-deficient ATG5 mutant K130R bypasses oncogenic Ras-induced senescence in ASPP2 wild type MEFs. Conversely, ATG5 or ATG3 depletion sensitizes MEFs to Ras-induced senescence. Taken together, these data indicate that different levels of autophagic activity may dictate the cellular response to Ras-induced senescence. In other words, high levels of autophagy bypass senescence and a significant reduction or lack of autophagy sensitizes mouse cells to senescence.

2.2. Opposing Roles of Autophagy in Cancer. During cancer progression, autophagy also plays discretely opposite roles. At the early stages of cancer, the antitumoral effect of autophagy is characterized by active maintenance of cellular quality control for cytosolic prooncogenic proteins, such as p62, to prevent malignant transformation of normal cells. Furthermore, the supply of energy provided through activation of autophagy reduces the dependence on glycolysis, while assuring the energy required for maintenance of a stable genome, further preventing oncogenesis $[18,19]$. The gradual reduction in autophagic activity at the end of the early stages of cancer development eventually favours malignant transformation of cells, as the accumulation of proteins like p62 activates signaling pathways that promote necrosis and inflammation. Poor quality control as a result of diminished autophagy can also lead to the accumulation of defective mitochondria, which release cytochrome $\mathrm{c}$ and reactive oxygen species (ROS) to further alter genome integrity. As cancer progresses into the later stages, reactivation of autophagy becomes necessary, in part to compensate for the poor nutritional supply associated with rapidly growing tumors and to defend cancer cells against damage induced by antioncogenic therapies. In cancer cells and tumors with activating mutations of $\mathrm{H}$-ras and $\mathrm{K}$-ras, the upregulation of autophagy appears to support the proper maintenance of mitochondrial metabolism for robust cell growth [11-13]. Enhanced removal of dysfunctional mitochondria may contribute to the upregulation of glycolysis to maintain the energetic balance (Warburg effect) characteristic of malignant cells in vitro and in vivo [11-14]. Importantly, inhibition of autophagy via genetic knockdown/knockout of autophagy-related genes or chloroquine treatment (to alter lysosomal $\mathrm{pH}$ ) leads to tumor regression in pancreatic cancer xenografts in mice [14]. Thus, the precise regulation of autophagy may be critical for transformation in these oncogenic Ras-activated cancer cells.

An interesting aspect of a subset of Ras-driven cancers (such as those of colonic, lung, and pancreatic origin) that the White, Kimmelman, Debnath, and Lee labs have described is their reliance on an elevated level of basal autophagy for survival [11-14]. For instance, human cancer cells with oncogenic Ras activation displayed high sensitivity to genetic impairment of essential autophagy proteins, ATG5 or ATG7, leading either to apoptosis or growth arrest [11]. Furthermore, Ras-driven proliferation and transformation of autophagycompetent cells appear to be more sensitive to diminished glucose availability than autophagy-deficient cells [13]. It is perhaps not entirely surprising that Ras-driven cancer cells hijack the autophagic recycling process to deal with the reprogramming of energy metabolism induced by oncogenic Ras. Persistent oncogenic Ras signaling may lead to the rapid depletion of biosynthetic intermediates from tricarboxylic 
acid (TCA) cycle and high energy demand for its anabolic programs. These quickly result in the impairment of mitochondrial respiration function and the accumulation of dysfunctional mitochondria. The failure to clear dysfunctional mitochondria from these cancer cells can be deleterious. To overcome this problem, it seems reasonable to propose that Ras-driven cancer cells rely on the catabolic nature of autophagy to rapidly derive biosynthetic intermediates from the cargoes of autolysosomes to fuel growth and survival, both in vitro and in vivo [20,21].

However, much remains to be answered in the interplay between autophagy and cellular metabolism during cancer progression. Apart from the PI3K/Akt/mTOR effector pathway of Ras signaling, do cancer cell utilize other signaling pathways to prevent self-cannibalism? What is the maximum threshold of autophagic vesicles that a Ras-driven cancer cell can contain before triggering its death signal? Is a Ras-driven cancer cell more sensitive to no autophagic recycling or too much autophagic recycling? In spite of all these questions, the White and Kimmelman labs demonstrate that targeting the autophagy pathway may be an effective therapeutic approach to combat Ras-driven cancers in mice and humans $[20,22]$.

\section{Role of Autophagy in Myc-Driven Cancers}

Following the discovery of Ras-induced autophagy by the White lab, one immediate question to be addressed is do other oncogenes also elevate the level of autophagic activity to favor carcinogenesis? Of note, the overexpression of c-Myc robustly induces autophagy in rat $3 \mathrm{Y} 1$ fibroblasts [23]. Koumenis and coworkers recently showed that the MYC oncogene activation elicits an adaptation-remodelling program called the unfolded protein response (UPR), where the module of the UPR containing PKR-like ER stress kinase (PERK) can promote tumorigenesis via endoplasmic reticulum (ER) stress-induced autophagy activation [24]. This new finding supports the idea that autophagy may be controlled by other oncogenes during cancer progression. In other words, cancers with oncogene addiction may also likely be addicted to autophagy as a secondary consequence.

The Myc family of protooncogenes consists of MYC, $M Y C L$, and $M Y C N$. It regulates gene transcription, cell-cycle progression, stemness, metabolic reprogramming, and many other important cellular processes [25]. Like RAS, MYC is frequently mutated in many human cancers. Chromosomal translocation, involving $M Y C$, has been found in multiple myeloma and Burkitt's lymphoma. In addition, MYCN is commonly amplified in neuroblastoma, small-cell lung cancer, medulloblastoma, and neuroendocrine prostate cancer [26]. Due to the oncogenic role that the Myc family plays in blood cancers and solid tumors, many researchers are in hot pursuit of therapeutically targeting the Myc family and/or the cellular processes regulated by these transcription factors. However, it remains a daunting task to design therapeutic strategies to directly target this family because of their unpredictable pleiotropic effects in the cell, and more importantly, these transcription factors do not have a druggable domain. Hence, targeting UPR or specific kinases like PERK may provide a feasible therapeutic avenue to combat Myc-driven malignancies.

\section{Targeting Oncogene-Induced Autophagy: A Novel Therapeutic Approach in Cancer Clinics}

Although careful and selective targeting of the components of autophagy in the right cancer cell types may yield beneficial outcomes in the treatment of aggressive cancers that are specifically driven by Ras, Myc, or other oncogenes, one needs to appreciate the complexity of pursuing such a novel therapeutic strategy in the oncology clinics. A number of reports have highlighted that many current anticancer regimens can either be cytotoxic or protective to cancer cells by promoting autophagy $[22,27,28]$. For example, autophagy can confer cytoprotection and chemoresistance to colon and esophageal cancer cells in response to 5-fluorouracil (5-FU) treatment $[29,30]$. Furthermore, elevated levels of autophagy can render breast cancer cells insensitive to ionizing radiation killing $[31,32]$. On the other hand, von Hippel-Lindau (VHL) tumor suppressor-null renal carcinoma cells treated with an inducer of autophagy, STF-62247, undergo cancer-selective cell death and a reduction of tumor burden in a mouse xenograft model [33].

Should clinicians promote or inhibit autophagy to improve prognostics of cancer patients, and what do they need to consider before including a growing list of autophagy modulators (Table 1) in their therapeutic strategies? There are several possible reasons that can explain such contradictory outcomes of targeting autophagy in different contexts. Firstly, reported small molecule modulators of autophagy and ATG genes-targeted ablation may hit targets other than those involved in the autophagic pathway. For instance, it has been discussed that a high dose of chloroquine (CQ), a common lysosomotropic agent, is capable of inhibiting other cellular pathways, such as those implicated in DNA damage and immune modulation [27]. Although existing preclinical reports have shown that cancer cells with increased autophagy undergo cell death in response to lysosomal inhibitors such as CQ [70], more studies need to be done to demonstrate unequivocally that these cytotoxic effects arise particularly from autophagy inhibition rather than from off-target lysosome-independent effects.

Secondly, inhibiting autophagy in different stages of cancer progression can lead to different therapeutic outcomes. For example, it was demonstrated that inhibition of autophagy at early stages attenuated imatinib-induced cytotoxicity in human malignant glioma. In contrast, imatinib-induced cytotoxicity was augmented only when the later stage of the autophagy pathway was inhibited [71]. In the case of liver cancer, preventing autophagy inhibition may play an important role in suppressing the development of hepatocarcinogenesis at the dysplastic stage by promoting cell stability. However, the inhibition of autophagy may be a useful strategy to combat hepatocarcinogenesis in the tumor-forming stage by enhancing ROS-mediated cellular damage and suppressing 
TABLE 1: Chemical modulators of autophagy and their modes of action.

\begin{tabular}{|c|c|c|c|c|}
\hline Compound & Mechanism & Cancer type & $\begin{array}{c}\text { Role of } \\
\text { autophagy }\end{array}$ & References \\
\hline \multicolumn{5}{|l|}{ Inducers of autophagy } \\
\hline AZD8055 & Inhibits mTORC1 activity & Nonsmall cell lung cancer & Prodeath & {$[34]$} \\
\hline Bortezomib & Blocks Bax degradation & $\begin{array}{l}\text { Chronic lymphocytic } \\
\text { leukemia }\end{array}$ & Prodeath & {$[35]$} \\
\hline Bufalin & $\begin{array}{l}\text { Synergizes with JNK pathway and increases expression } \\
\text { of TNF, BECN-1, MAPK, and ATG8 }\end{array}$ & $\begin{array}{l}\text { Liver cancer } \\
\text { Colorectal cancer }\end{array}$ & $\begin{array}{l}\text { Prodeath } \\
\text { Prodeath }\end{array}$ & $\begin{array}{l}{[36]} \\
{[37]}\end{array}$ \\
\hline Chlorpromazine & Inhibits PI3K/Akt/mTOR signaling pathway & Brain cancer & Prodeath & {$[38]$} \\
\hline Cisplatin & Activation of AMPK signaling pathway & Liver cancer & Prodeath & [39] \\
\hline $\begin{array}{l}\text { Compound C } \\
\text { (Dorsomorphin) }\end{array}$ & Inhibits AMPK activity & Colorectal cancer & Prodeath & {$[40]$} \\
\hline Everolimus & Inhibits mTORCl activity & $\begin{array}{l}\text { Acute lymphoblastic } \\
\text { leukemia } \\
\text { Prostate cancer }\end{array}$ & $\begin{array}{l}\text { Prodeath } \\
\text { Prodeath }\end{array}$ & $\begin{array}{l}{[41]} \\
{[42]}\end{array}$ \\
\hline Fangchinoline & $\begin{array}{l}\text { Transactivation of sestrin } 2 \text { gene, leading to AMPK } \\
\text { signaling activation }\end{array}$ & Liver cancer & Prodeath & {$[43]$} \\
\hline Imatinib & Increases expression of Beclin-1 and ATG5 & $\begin{array}{l}\text { Chronic myeloid leukemia } \\
\text { Gastrointestinal stromal } \\
\text { tumor }\end{array}$ & $\begin{array}{l}\text { Prodeath } \\
\text { Prosurvival }\end{array}$ & $\begin{array}{l}{[44]} \\
{[45]}\end{array}$ \\
\hline Nilotinib & $\begin{array}{l}\text { Induces PP2A-regulated AMPK phosphorylation and } \\
\text { activation }\end{array}$ & Liver cancer & Prodeath & {$[46]$} \\
\hline Obatoclax (GX15-070) & Induces ATG5-dependent autophagic cell death & $\begin{array}{l}\text { Acute lymphoblastic } \\
\text { leukemia }\end{array}$ & Prodeath & {$[47]$} \\
\hline Pemetrexed & $\begin{array}{l}\text { Increases levels of Akt, p70 S6K, and/or } \\
\text { phosphorylated-mTOR }\end{array}$ & Nonsmall cell lung cancer & Prodeath & {$[48]$} \\
\hline Perifosine & Inhibits PI3K/Akt/mTOR signaling pathway & Chronic myeloid leukemia & Prosurvival & {$[49]$} \\
\hline PI-103 hydrochloride & Inhibits PI3K/Akt/mTOR signaling pathway & Brain cancer & Prodeath & {$[50]$} \\
\hline PP242 & Inhibits mTORC1 activity & Multiple cancers & Prodeath & {$[51]$} \\
\hline Resveratrol & $\begin{array}{l}\text { Accumulation of intracellular calcium and activation of } \\
\text { AMPK/mTOR signaling pathway }\end{array}$ & Nonsmall cell lung cancer & Prodeath & {$[52]$} \\
\hline Safingol & $\begin{array}{l}\text { Increases ROS and/or AMPK activation } \\
\text { Inhibits PKCs and PI3K pathway directly }\end{array}$ & $\begin{array}{l}\text { Breast cancer } \\
\text { Colorectal cancer }\end{array}$ & $\begin{array}{l}\text { Prodeath } \\
\text { Prodeath }\end{array}$ & $\begin{array}{l}{[53]} \\
{[54]}\end{array}$ \\
\hline Salinomycin & $\begin{array}{l}\text { Increases ER stress via } \\
\text { ATF4-DDIT3/CHOP-TRIB3-Akt-mTOR signaling } \\
\text { pathway }\end{array}$ & Nonsmall cell lung cancer & Prodeath & {$[55]$} \\
\hline Sodium selenite & $\begin{array}{l}\text { Activates Nrf2 } \\
\text { Dephosphorylates PP2A and lead to DAPK activation }\end{array}$ & $\begin{array}{l}\text { Nonsmall cell lung cancer } \\
\text { Promyelocytic leukemia }\end{array}$ & $\begin{array}{l}\text { Prosurvival } \\
\text { Prodeath }\end{array}$ & $\begin{array}{l}{[56]} \\
{[57]}\end{array}$ \\
\hline $\begin{array}{l}\text { Sorafenib } \\
\text { SC-59 (Sorafenib } \\
\text { derivative) }\end{array}$ & $\begin{array}{l}\text { Inhibits phospho-STAT3 signaling pathway and reduces } \\
\text { expression of myeloid cell leukemia (MCL-1), which } \\
\text { disrupts Beclin-1-Mcl-1 complex }\end{array}$ & $\begin{array}{l}\text { Brain, breast, liver, and lung } \\
\text { cancers }\end{array}$ & $\begin{array}{l}\text { Prodeath } \\
\text { Prodeath }\end{array}$ & {$[48]$} \\
\hline STF-62247 & PI3K signaling pathway and golgi trafficking & VHL-deficient renal cancer & Prodeath & {$[33]$} \\
\hline Temsirolimus & Inhibits mTORC1 activity & Mantle cell lymphoma & Prodeath & {$[59]$} \\
\hline Torin-1 & $\begin{array}{l}\text { ATP-competitive mTOR inhibitor that inhibits both } \\
\text { mTORC1 and mTORC } 2 \text { directly }\end{array}$ & Multiple cancers & Prodeath & {$[60]$} \\
\hline Wogonin & Inhibits p70S6K/Akt pathway & Nasopharyngeal cancer & Prodeath & {$[61]$} \\
\hline \multicolumn{5}{|l|}{ Inhibitors of autophagy } \\
\hline $\begin{array}{l}\text { 3-Methyladenine } \\
\text { (3-MA) }\end{array}$ & Inhibits PI3K signaling pathway & $\begin{array}{l}\text { Colorectal cancer } \\
\text { Esophageal cancer }\end{array}$ & $\begin{array}{l}\text { Prosurvival } \\
\text { Prosurvival }\end{array}$ & $\begin{array}{l}{[62]} \\
{[63]}\end{array}$ \\
\hline Bafilomycin A1 & $\begin{array}{l}\text { Prevents fusion of autophagosomes with lysosomes by } \\
\text { acting as a V-ATPase inhibitor }\end{array}$ & $\begin{array}{l}\text { Breast cancer } \\
\text { Colorectal cancer }\end{array}$ & $\begin{array}{l}\text { Prosurvival } \\
\text { Prosurvival }\end{array}$ & $\begin{array}{l}{[64]} \\
{[65]}\end{array}$ \\
\hline Chloroquine & $\begin{array}{l}\text { Inhibits lysosomal acidification and prevents fusion of } \\
\text { autophagosomes with lysosomes }\end{array}$ & $\begin{array}{l}\text { Brain cancer } \\
\text { Colorectal cancer }\end{array}$ & $\begin{array}{l}\text { Prosurvival } \\
\text { Prosurvival }\end{array}$ & $\begin{array}{l}{[66]} \\
{[67]}\end{array}$ \\
\hline
\end{tabular}


TABle 1: Continued.

\begin{tabular}{|c|c|c|c|c|}
\hline Compound & Mechanism & Cancer type & $\begin{array}{c}\text { Role of } \\
\text { autophagy }\end{array}$ & References \\
\hline Lucanthone & $\begin{array}{l}\text { Induces vacuolization and interferes with lysosomal } \\
\text { function }\end{array}$ & Breast cancer & Prodeath & {$[68]$} \\
\hline Spautin-1 & Promotes ubiquitylation of Beclin-1 & Breast cancer & Prodeath & {$[69]$} \\
\hline
\end{tabular}

cell metabolism [72]. Hence, we envisage that the development of diagnostic tools to specifically monitor the dynamic changes in the autophagy pathway in vivo will provide more precise interpretation of experimental or treatment outcomes. The recent creation of GFP-LC3 transgenic mouse [73] to study the dynamic changes in autophagic response to genetic or pharmacological manipulations has been unanimously hailed as a significant breakthrough, but it remains technically demanding to extend this scientific advancement to human patients at this point in time.

Thirdly, the discordant outcomes of targeting autophagy could be due to the specificity of approaches used to modulate and measure autophagy. Immunohistochemical staining to detect changes in LC3 expression levels remains as the most direct functional readout for autophagic processing. However, given the dynamic and complex process of autophagy, potential caveats exist when LC3 immunostaining data are being interpreted. Indeed, it has been reported that LC3 expression levels can differ significantly between cell types and conditions. Hence, immunostaining assays reflect only a static "snapshot in time" and not a true representation of the overall autophagic flux in cancer cells [74]. These discrepancies in measuring the extent of autophagic response may eventually lead to gross data misinterpretation. We support the notion that the differential scoring of cells undergoing death upon therapeutic treatments could be performed by taking account of the cell type, cell growth kinetics, and stages of tumor progression. Alternatively, the difference in selecting experimental end points in a timed study may also lead to differential cell survival outcomes [75].

Clearly, more should be done to delineate the role of autophagy in cancer therapy. Importantly, we should define and identify which cancer subtypes would exhibit higher sensitivity to autophagic modulation. According to findings from the White lab, oncogenic Ras-driven cancers appear to be particularly sensitive to the inhibition of autophagy $[14,20]$. This observation seems to be at odds with the wide-accepted dogma that the PI3K/Akt/mTOR signaling axis, which is one of the three major Ras effector pathways, suppresses autophagy. Perhaps one way to explain this discrepancy is that Ras-driven cancers thrive on their ability to tightly control the increase in basal autophagy and that this mode of regulation on basal autophagy status will be lost, following inhibition of the PI3K/Akt/mTOR signaling cascade by either genetic or pharmacologic means. For example, rapamycin is a naturally occurring allosteric mTOR inhibitor, and its analogs temsirolimus (CCI-779), everolimus (RAD001), and deforolimus (AP-23573) selectively target mTORC1 to stimulate autophagy. However, with the exception of renal cell and neuroendocrine carcinomas and lymphoma, rapamycin and its analogs (rapalogs) showed little efficacy in the clinical setting [76]. This may be attributed to the fact that rapamycin and rapalogs fail to inhibit mTORC2 activity and are thus unable to abrogate the S6K/IRS1mediated negative feedback that induces AKT reactivation [77]. These limitations are circumvented by the development of ATP-competitive inhibitors of both mTORC1 and mTORC2 (e.g., PP242, Torin1, AZD8055, and WYE132) and the dual PI3K-mTOR inhibitor, NVP-BEZ235. In preclinical studies, dual inhibitors of mTORC1 and mTORC2 showed superior anticancer activity $[34,78,79]$ and were shown to be more potent autophagy inducers compared to mTORC1 inhibitors alone $[60,80]$. Notably, the dual PI3K-mTOR inhibitor PI-103 only induces autophagy in glioma cells and cancer cell killing via apoptosis was achieved when it was combined with autophagy inhibitors. In addition, the PI3KmTOR inhibitors, NVP-BEZ235 and XL765, synergize with CQ in the induction of apoptosis in glioma and malignant peripheral nerve sheath tumor xenografts, respectively [81, 82]. It remains unclear whether the use of these dual PI3KmTOR inhibitors alone will induce autophagy that will further fuel cancer progression.

Apart from PI3K pathway inhibitors, many ongoing studies and clinical trials are aiming to repurpose the antimalarial lysosomotropic drugs, CQ and hydroxychloroquine (HCQ), as anticancer therapeutics via the inhibition of lysosomal degradation of autophagic cargo and preferential killing of mouse cells expressing MYC oncogene in a p53-dependent manner. In addition, inhibition of autophagy can induce apoptosis and delay tumor recurrence following p53 reactivation in a p53-null, Myc-induced lymphoma mouse model $[21,22,27,91,92]$. At the face value, CQ and HCQ appear to be good anticancer drug candidates because they are well tolerated and safe for human use $[64,93,94]$. However, in most Ras-driven human cancer cell lines that are dependent on an elevated level of basal autophagy a suprahigh dose of CQ is required for growth inhibition [11]. This may be attributed to poor pharmacokinetics of CQ and low potency of the drug to inhibit autophagy [94]. In other words, only a high dose of these lysosomotropic drugs can induce the accumulation of ineffective autophagic vesicles beyond a certain threshold that is tolerable to the cell. Hence, one feasible way to maximize cancer cell growth inhibition/killing may likely be the optimal combination of autophagy inducers, inhibitors, and/or other anticancer regimens (Table 2).

Indeed, drug combination therapy has recently emerged as a promising alternative anticancer strategy [27]. For 
TABLE 2: Preclinical trials evaluating the potential of combinatorial drug therapies as anticancer treatments.

\begin{tabular}{|c|c|c|c|c|}
\hline \multicolumn{5}{|c|}{ Combinatorial drug therapies } \\
\hline Compounds & Mechanism & Cancer type & $\begin{array}{c}\text { Role of } \\
\text { autophagy }\end{array}$ & References \\
\hline \multirow{2}{*}{ 5-Flurouracil and si-Beclin-1 } & \multirow{2}{*}{ Inhibit nucleic acid synthesis } & Esophageal cancer & Prodeath & [29] \\
\hline & & Liver cancer & Prodeath & [39] \\
\hline $\begin{array}{l}\text { CQ, Oxaliplatin and } \\
\text { Bevacizumab }\end{array}$ & $\begin{array}{l}\text { Inhibition of autophagy by CQ sensitizes cells to } \\
\text { Oxaliplatin and Bevacizumab treatment }\end{array}$ & Colorectal cancer & Prodeath & {$[83]$} \\
\hline Compound $\mathrm{C}$ and Bafilomycin & Inhibit AMPK activity & Brain cancer & Prodeath & {$[84]$} \\
\hline CQ and ADZ5363 & $\begin{array}{l}\text { Inhibit Akt signaling pathway downstream and } \\
\text { reduce phosphorylated-mTOR and } \\
\text { p-RPS6KB/p70S6K }\end{array}$ & Prostate cancer & Prodeath & {$[85]$} \\
\hline CQ and NVP-BEZ235 & Inhibition of autophagy by CQ sensitizes cells to & Brain cancer & Prodeath & {$[81]$} \\
\hline CQ and XL765 & dual PI3K/mTOR treatment & Dram cancer & Prodeath & {$[82]$} \\
\hline Gemcitabine and Cannabinoid & Increase ceramide & Pancreatic cancer & Prodeath & {$[86]$} \\
\hline Lucanthone and Vorinostat & $\begin{array}{l}\text { Enhance activity of histone deacetylase inhibitor, } \\
\text { Vorinostat }\end{array}$ & Breast cancer & Prodeath & {$[68]$} \\
\hline Obatoclax and Lapatinib & $\begin{array}{l}\text { Increase expression of NOXA, leading to } \\
\text { displacement of Mcl-1 from Beclin-1 }\end{array}$ & Breast cancer & Prodeath & {$[87]$} \\
\hline Pyrvinium pamoate and 2-DG & $\begin{array}{l}\text { Pyrvinium pamoate inhibits 2-DG-triggered } \\
\text { accumulation of LC3 puncta }\end{array}$ & $\begin{array}{l}\text { Cervical cancer } \\
\text { Colorectal cancer }\end{array}$ & $\begin{array}{l}\text { Prodeath } \\
\text { Prodeath }\end{array}$ & {$[88]$} \\
\hline Sorafenib and Pemetrexed & $\begin{array}{l}\text { Increase levels of Akt, p70 S6K, and/or } \\
\text { phosphorylated-mTOR }\end{array}$ & $\begin{array}{l}\text { Brain, breast, liver, and } \\
\text { lung cancers }\end{array}$ & Prodeath & {$[48]$} \\
\hline Tamoxifen and deacetylase & $\begin{array}{l}\text { Prevent HMGB1: Beclin-1-mediated autophagy } \\
\text { from promoting drug resistance }\end{array}$ & Osteosarcoma & Prodeath & {$[89]$} \\
\hline Valproic acid and Tubacin & Inhibit HDAC6 specifically & Ovarian cancer & Prodeath & {$[90]$} \\
\hline
\end{tabular}

instance, human colon cancer lines treated with a combination of Oxaliplatin, Bevacizumab, and chloroquine result in a significant reduction in tumor growth in a synergistic manner [83]. Given that successful drug combination therapies have been reported in many recent studies [83, 95-97], we support the idea that an increasing number of ongoing and future clinical trials will explore the amalgamation use of autophagic modulators with other treatment modalities, such as radiation or chemotherapy, to potentiate its antitumorigenic effect [27]. However, the cellular effect of these combination therapies involving autophagy modulation is likely to be complex and requires thorough understanding of their mechanism of action prior to their deployment in the clinics. For example, the capacity for sensitization by CQ appears to be quite wide ranging, with dramatic effects for some drugs/tumor models and modest or minimal effects in others. We noted a recent study published by Bristol et al. demonstrating that neither chloroquine nor silencing of an autophagy regulatory gene was effective in conferring radiation sensitivity in the 4T1 syngeneic mouse breast tumor model [98]. Bristol et al. argued that a fully functional immune system may play a central role in determining the effectiveness of autophagy inhibition in chemosensitization or radiosensitization, since most successful combination therapies involving autophagy modulation have generally been performed in xenograft models. This study opens a new Pandora's box that suggests the existence of many other unknown determinants of autophagy-targeting combination cancer therapies. Hence, much remains to be done to investigate whether experimental findings from in vitro cultured human cancer cells and in vivo animal models of cancers can ultimately be translated to humans.

\section{Concluding Remarks}

Similar to its bilateral roles as both a tumour suppressor and prosurvival mediator in cancer progression, autophagy can have cytotoxic and protective roles in anticancer therapies [8]. Depending on different cellular conditions and distinct cancer subtypes, the role of autophagy can vary significantly. In addition to sustaining cancer cell survival in response to environmental and metabolic stress, autophagy is also utilized by normal cells to maintain cellular homeostasis. Even though autophagy inhibitors can be exploited as alternative anticancer therapeutics, we ought to be mindful that their nonselective usage can also inflict serious collateral damages on normal tissues at the same time. In this regard, we need a better understanding of how signaling pathways or other cellular processes govern oncogene-induced autophagic responses. This will allow us to target important proteins of these signaling pathways or cellular processes that regulate autophagy specifically. As autophagy inhibitors proceed into early clinical trial phase to treat oncogenic Rasdriven cancers in human, future work will shed light on whether targeting Ras/Myc-, or at large, oncogene-induced autophagy is a viable anticancer therapeutic strategy. 


\section{Conflict of Interests}

The authors declare that they have no conflict of interests.

\section{Authors' Contribution}

Fuquan Zhang wrote the paper. Jit Kong Cheong edited the paper.

\section{Acknowledgments}

The authors thank David Virshup (Duke-NUS Graduate Medical School, Singapore), Shazib Pervaiz (National University of Singapore) and Andrew Thorburn (University of Colorado, Denver, USA) for their helpful and insightful discussions. Jit Kong Cheong is supported by the National Medical Research Council (NMRC) New Investigator Grant (NMRC/BNIG/1078/2012).

\section{References}

[1] K. Takeshige, M. Baba, S. Tsuboi, T. Noda, and Y. Ohsumi, "Autophagy in yeast demonstrated with proteinase-deficient mutants and conditions for its induction," Journal of Cell Biology, vol. 119, no. 2, pp. 301-312, 1992.

[2] D. J. Klionsky, "Autophagy: from phenomenology to molecular understanding in less than a decade," Nature Reviews Molecular Cell Biology, vol. 8, no. 11, pp. 931-937, 2007.

[3] B. Ravikumar, M. Futter, L. Jahreiss et al., "Mammalian macroautophagy at a glance," Journal of Cell Science, vol. 122, no. 11, pp. 1707-1711, 2009.

[4] J. K. Lennerz, J. B. Hurov, L. S. White et al., "Loss of Par-la/ MARK3/C-TAK1 kinase leads to reduced adiposity, resistance to hepatic steatosis, and defective gluconeogenesis," Molecular and Cellular Biology, vol. 30, no. 21, pp. 5043-5056, 2010.

[5] B. Dehay, J. Bové, N. Rodríguez-Muela et al., "Pathogenic lysosomal depletion in Parkinson's disease," Journal of Neuroscience, vol. 30, no. 37, pp. 12535-12544, 2010.

[6] S. J. Martin, "Oncogene-induced autophagy and the Goldilocks principle," Autophagy, vol. 7, no. 8, pp. 922-923, 2011.

[7] A. C. Kimmelman, "The dynamic nature of autophagy in cancer," Genes and Development, vol. 25, no. 19, pp. 1999-2010, 2011.

[8] E. White and R. S. DiPaola, "The double-edged sword of autophagy modulation in cancer," Clinical Cancer Research, vol. 15, no. 17, pp. 5308-5316, 2009.

[9] Y. Pylayeva-Gupta, E. Grabocka, and D. Bar-Sagi, "RAS oncogenes: weaving a tumorigenic web," Nature Reviews Cancer, vol. 11, no. 11, pp. 761-774, 2011.

[10] J. Downward, “Targeting RAS signalling pathways in cancer therapy," Nature Reviews Cancer, vol. 3, no. 1, pp. 11-22, 2003.

[11] J. Y. Guo, H.-Y. Chen, R. Mathew et al., "Activated Ras requires autophagy to maintain oxidative metabolism and tumorigenesis," Genes and Development, vol. 25, no. 5, pp. 460-470, 2011.

[12] M.-J. Kim, S.-J. Woo, C.-H. Yoon et al., "Involvement of autophagy in oncogenic K-Ras-induced malignant cell transformation," Journal of Biological Chemistry, vol. 286, no. 15, pp. 1292412932, 2011.

[13] R. Lock, S. Roy, C. M. Kenific et al., "Autophagy facilitates glycolysis during Ras-mediated oncogenic transformation," Molecular Biology of the Cell, vol. 22, no. 2, pp. 165-178, 2011.
[14] S. Yang, X. Wang, G. Contino et al., "Pancreatic cancers require autophagy for tumor growth," Genes and Development, vol. 25, no. 7, pp. 717-729, 2011.

[15] M. Elgendy, C. Sheridan, G. Brumatti, and S. J. Martin, “Oncogenic Ras-induced expression of noxa and beclin-1 promotes autophagic cell death and limits clonogenic survival," Molecular Cell, vol. 42, no. 1, pp. 23-35, 2011.

[16] G. Mariño, I. Martins, and G. Kroemer, "Autophagy in Rasinduced malignant transformation: fatal or vital?" Molecular Cell, vol. 42, no. 1, pp. 1-3, 2011.

[17] Y. Wang, Y. W. X, E. Lapi, A. Sullivan, W. Jia et al., "Autophagic activity dictates the cellular response to oncogenic RAS," Proceedings of the National Academy of Sciences, vol. 109, pp. 1332513330, 2012.

[18] R. G. Jones and C. B. Thompson, "Tumor suppressors and cell metabolism: a recipe for cancer growth," Genes and Development, vol. 23, no. 5, pp. 537-548, 2009.

[19] C. H. Eng and R. T. Abraham, "The autophagy conundrum in cancer: influence of tumorigenic metabolic reprogramming," Oncogene, vol. 30, no. 47, pp. 4687-4696, 2011.

[20] E. White, "Deconvoluting the context-dependent role for autophagy in cancer," Nature Reviews Cancer, vol. 12, pp. 401-410.

[21] E. Y. Liu and K. M. Ryan, "Autophagy and cancer-issues we need to digest," Journal of Cell Science, vol. 125, pp. 2349-2358, 2012.

[22] J. D. Mancias and A. C. Kimmelman, "Targeting autophagy addiction in cancer," Oncotarget, vol. 2, pp. 1302-1306, 2011.

[23] M. Tsuneoka, T. Umata, H. Kimura et al., "c-myc induces autophagy in rat $3 \mathrm{Y} 1$ fibroblast cells," Cell Structure and Function, vol. 28, no. 3, pp. 195-204, 2003.

[24] L. S. Hart, L. S. C. J, T. Datta, S. Dey, F. Tameire et al., "ER stressmediated autophagy promotes Myc-dependent transformation and tumor growth," Journal of Clinical Investigation, vol. 122, pp. 4621-4634, 2012.

[25] R. C. Sears, "The life cycle of c-Myc: from synthesis to degradation," Cell Cycle, vol. 3, no. 9, pp. 1133-1137, 2004.

[26] C. V. Dang, "MYC on the path to cancer," Cell, vol. 149, no. 1, pp. 22-35, 2012.

[27] N. Chen and V. Karantza, "Autophagy as a therapeutic target in cancer," Cancer Biology and Therapy, vol. 11, no. 2, pp. 157-168, 2011.

[28] S. Chen, S. K. Rehman, W. Zhang, A. Wen, L. Yao, and J. Zhang, "Autophagy is a therapeutic target in anticancer drug resistance," Biochimica et Biophysica Acta, vol. 1806, no. 2, pp. 220 229, 2010.

[29] T. R. O’Donovan, G. C. O'Sullivan, and S. L. McKenna, "Induction of autophagy by drug-resistant esophageal cancer cells promotes their survival and recovery following treatment with chemotherapeutics," Autophagy, vol. 7, no. 5, pp. 509-524, 2011.

[30] J. Li, N. Hou, A. Faried, S. Tsutsumi, and H. Kuwano, "Inhibition of autophagy augments 5-fluorouracil chemotherapy in human colon cancer in vitro and in vivo model," European Journal of Cancer, vol. 46, no. 10, pp. 1900-1909, 2010.

[31] S. Palumbo and S. Comincini, "Autophagy and ionizing radiation in tumors: the "survive or not survive" dilemma," Journal of Cellular Physiology, vol. 228, pp. 1-8, 2013.

[32] H. Chaachouay, P. Ohneseit, M. Toulany, R. Kehlbach, G. Multhoff, and H. P. Rodemann, "Autophagy contributes to resistance of tumor cells to ionizing radiation," Radiotherapy and Oncology, vol. 99, no. 3, pp. 287-292, 2011. 
[33] S. Turcotte, D. A. Chan, P. D. Sutphin, M. P. Hay, W. A. Denny, and A. J. Giaccia, "A molecule targeting VHL-deficient renal cell carcinoma that induces autophagy," Cancer Cell, vol. 14, no. 1, pp. 90-102, 2008.

[34] C. M. Chresta, B. R. Davies, I. Hickson et al., "AZD8055 is a potent, selective, and orally bioavailable ATP-competitive mammalian target of rapamycin kinase inhibitor with in vitro and in vivo antitumor activity," Cancer Research, vol. 70, no. 1, pp. 288-298, 2010.

[35] F.-T. Liu, S. G. Agrawal, J. G. Gribben et al., "Bortezomib blocks Bax degradation in malignant $\mathrm{B}$ cells during treatment with TRAIL," Blood, vol. 111, no. 5, pp. 2797-2805, 2008.

[36] C.-M. Hsu, Y. Tsai, L. Wan, and F.-J. Tsai, "Bufalin induces G2/M phase arrest and triggers autophagy via the TNF, JNK, BECN1 and ATG8 pathway in human hepatoma cells," International Journal of Oncology, vol. 43, no. 1, pp. 338-348, 2013.

[37] C.-M. Xie, W. Y. Chan, S. Yu, J. Zhao, and C. H. K. Cheng, "Bufalin induces autophagy-mediated cell death in human colon cancer cells through reactive oxygen species generation and JNK activation," Free Radical Biology and Medicine, vol. 51, no. 7, pp. 1365-1375, 2011.

[38] S. Y. Shin, K. S. Lee, Y.-K. Choi, H. J. Lim, H. G. Lee et al., "The antipsychotic agent chlorpromazine induces autophagic cell death by inhibiting Akt/mTOR pathway in human U-87MG glioma cells," Carcinogenesis, 2013.

[39] X.-L. Guo, D. Li, F. Hu et al., "Targeting autophagy potentiates chemotherapy-induced apoptosis and proliferation inhibition in hepatocarcinoma cells," Cancer Letters, vol. 320, no. 2, pp. 171179, 2012.

[40] W.-L. Yang, W. P. W, D. Liou, P. Marambaud, and P. Wang, "AMPK inhibitor compound C suppresses cell proliferation by induction of apoptosis and autophagy in human colorectal cancer cells," Journal of Surgical Oncology, vol. 106, pp. 680-688, 2012.

[41] R. Crazzolara, K. F. Bradstock, and L. J. Bendall, "RAD001 (everolimus) induces autophagy in acute lymphoblastic leukemia," Autophagy, vol. 5, no. 5, pp. 727-728, 2009.

[42] C. Cao, T. Subhawong, J. M. Albert et al., "Inhibition of mammalian target of rapamycin or apoptotic pathway induces autophagy and radiosensitizes PTEN null prostate cancer cells," Cancer Research, vol. 66, no. 20, pp. 10040-10047, 2006.

[43] N. Wang, W. Pan, M. Zhu et al., "Fangchinoline induces autophagic cell death via p53/sestrin2/AMPK signalling in human hepatocellular carcinoma cells," British Journal of Pharmacology, vol. 164, no. 2, pp. 731-742, 2011.

[44] G. Can, H. A. Ekiz, and Y. Baran, "Imatinib induces autophagy through BECLIN-1 and ATG5 genes in chronic myeloid leukemia cells," Hematology, vol. 16, no. 2, pp. 95-99, 2011.

[45] A. Gupta, S. Roy, A. J. F. Lazar et al., "Autophagy inhibition and antimalarials promote cell death in gastrointestinal stromal tumor (GIST)," Proceedings of the National Academy of Sciences of the United States of America, vol. 107, no. 32, pp. 14333-14338, 2010.

[46] H. C. Yu, C. S. Lin, W. T. Tai, C. Y. Liu, C. W. Shiau, and K. F. Chen, "Nilotinib induces autophagy in hepatocellular carcinoma through AMPK activation," Journal of Biological Chemistry. In press.

[47] N. Heidari, M. A. Hicks, and H. Harada, "GX15-070 (obatoclax) overcomes glucocorticoid resistance in acute lymphoblastic leukemia through induction of apoptosis and autophagy," Cell Death and Disease, vol. 1, no. 9, article e76, 2010.
[48] M. D. Bareford, M. A. Park, A. Yacoub et al., "Sorafenib enhances pemetrexed cytotoxicity through an autophagy-dependent mechanism in cancer cells," Cancer Research, vol. 71, no. 14, pp. 4955-4967, 2011.

[49] Y. Tong, Y.-Y. Liu, L.-S. You, and W.-B. Qian, "Perifosine induces protective autophagy and upregulation of ATG5 in human chronic myelogenous leukemia cells in vitro," Acta Pharmacologica Sinica, vol. 33, no. 4, pp. 542-550, 2012.

[50] M. Degtyarev, A. De Mazière, C. Orr et al., "Akt inhibition promotes autophagy and sensitizes PTEN-null tumors to lysosomotropic agents," Journal of Cell Biology, vol. 183, no. 1, pp. 101-116, 2008.

[51] J. Zhou, S. H. Tan, V. Nicolas, C. Bauvy, N.-D. Yang et al., "Activation of lysosomal function in the course of autophagy via mTORC1 suppression and autophagosome-lysosome fusion," Cell Research, vol. 23, pp. 508-523, 2013.

[52] J. Zhang, H. Zhang, T. Qi et al., "Autophagic cell death induced by resveratrol depends on the $\mathrm{Ca}^{2+} / \mathrm{AMPK} / \mathrm{mTOR}$ pathway in A549 cells," Biochemical Pharmacology, 2013.

[53] L.-U. Ling, K.-B. Tan, H. Lin, and G. N. C. Chiu, "The role of reactive oxygen species and autophagy in safingol-induced cell death," Cell Death and Disease, vol. 2, no. 3, article e129, 2011.

[54] J. Coward, G. Ambrosini, E. Musi et al., "Safingol (L-threosphinganine) induces autophagy in solid tumor cells through inhibition of PKC and the PI3-kinase pathway," Autophagy, vol. 5, no. 2, pp. 184-193, 2009.

[55] T. Li, L. Su, N. Zhong, X. Hao, D. Zhong et al., "Salinomycin induces cell death with autophagy through activation of endoplasmic reticulum stress in human cancer cells," Autophagy, vol. 9, no. 7, 2013.

[56] S.-H. Park, J. H. Kim, G. Y. Chi, G.-Y. Kim, Y.-C. Chang et al., "Induction of apoptosis and autophagy by sodium selenite in A549 human lung carcinoma cells through generation of reactive oxygen species," Toxicology Letters, vol. 212, pp. 252-261, 2012.

[57] Q. Jiang, F. Li, K. Shi, Y. Yang, and C. Xu, "Sodium seleniteinduced activation of DAPK promotes autophagy in human leukemia HL60 cells," BMB Reports, vol. 45, pp. 194-199, 2012.

[58] W. T. Tai, C. W. Shiau, H.-L. Chen, C. Y. Liu, C. S. Lin et al., "Mcl-1-dependent activation of Beclin 1 mediates autophagic cell death induced by sorafenib and SC-59 in hepatocellular carcinoma cells," Cell Death and Disease, vol. 4, Article ID e485, 2013.

[59] V. Y. Yazbeck, D. Buglio, G. V. Georgakis et al., "Temsirolimus downregulates p21 without altering cyclin D1 expression and induces autophagy and synergizes with vorinostat in mantle cell lymphoma," Experimental Hematology, vol. 36, no. 4, pp. 443450, 2008.

[60] C. C. Thoreen, S. A. Kang, J. W. Chang et al., "An ATP-competitive mammalian target of rapamycin inhibitor reveals rapamycin-resistant functions of mTORC1," Journal of Biological Chemistry, vol. 284, no. 12, pp. 8023-8032, 2009.

[61] S.-E. Chow, Y. W. Chen, C.-A. Liang, Y.-K. Huang, and J.-S. Wang, "Wogonin induces cross-regulation between autophagy and apoptosis via a variety of Akt pathway in human nasopharyngeal carcinoma cells," Journal of Cellular Biochemistry, vol. 113, pp. 3476-3485, 2012.

[62] J. Li, N. Hou, A. Faried, S. Tsutsumi, T. Takeuchi, and H. Kuwano, "Inhibition of autophagy by 3-MA enhances the effect of 5FU-induced apoptosis in colon cancer cells," Annals of Surgical Oncology, vol. 16, no. 3, pp. 761-771, 2009. 
[63] D. Liu, Y. Yang, Q. Liu, and J. Wang, "Inhibition of autophagy by 3-MA potentiates cisplatin-induced apoptosis in esophageal squamous cell carcinoma cells," Medical Oncology, vol. 28, no. 1, pp. 105-111, 2011.

[64] S. E. Tett, R. O. Day, and D. J. Cutler, "Concentration-effect relationship of hydroxychloroquine in rheumatoid arthritis-a cross sectional study," Journal of Rheumatology, vol. 20, no. 11, pp. 1874-1879, 1993.

[65] G. J. Cerniglia, J. Karar, S. Tyagi, M. Christofidou-Solomidou, R. Rengan et al., "Inhibition of autophagy as a strategy to augment radiosensitization by the dual phosphatidylinositol 3-kinase/mammalian target of rapamycin inhibitor NVP-BEZ235," Molecular Pharmacology, vol. 82, pp. 1230-1240, 2012.

[66] Y. Geng, L. Kohli, B. J. Klocke, and K. A. Roth, "Chloroquineinduced autophagic vacuole accumulation and cell death in glioma cells is p53 independent," Neuro-Oncology, vol. 12, no. 5, pp. 473-481, 2010.

[67] K. Sasaki, N. H. Tsuno, E. Sunami et al., "Chloroquine potentiates the anti-cancer effect of 5-fluorouracil on colon cancer cells," BMC Cancer, vol. 10, article 370, 2010.

[68] J. S. Carew, C. M. Espitia, J. A. Esquivel II et al., "Lucanthone is a novel inhibitor of autophagy that induces cathepsin D-mediated apoptosis," Journal of Biological Chemistry, vol. 286, no. 8, pp. 6602-6613, 2011.

[69] J. Liu, H. Xia, M. Kim et al., "Beclinl controls the levels of p53 by regulating the deubiquitination activity of USP10 and USP13," Cell, vol. 147, no. 1, pp. 223-234, 2011.

[70] L. Verschooten, K. Barrette, S. Van Kelst, N. Rubio Romero, C. Proby et al., "Autophagy inhibitor chloroquine enhanced the cell death inducing effect of the flavonoid luteolin in metastatic squamous cell carcinoma cells," PLoS ONE, vol. 7, Article ID e48264, 2012.

[71] T. Shimgu, K. Fujiwara, O. Bogler et al., "Inhibition of autophagy at a late stage enhances imatinib-induced cytotoxicity In human malignant glioma cells," International Journal of Cancer, vol. 124, no. 5, pp. 1060-1071, 2009.

[72] K. Sun, X. L. Guo, Q. D. Zhao, Y. Y. Jing et al., "Paradoxical role of autophagy in the dysplastic and tumor-forming stages of hepatocarcinoma development in rats," Cell Death and Disease, vol. 4, Article ID e501, 2013.

[73] N. Mizushima, "Chapter 2 methods for monitoring autophagy using GFP-LC3 transgenic mice," Methods in Enzymology, vol. 451, pp. 13-23, 2009.

[74] S. Barth, D. Glick, and K. F. Macleod, "Autophagy: assays and artifacts," Journal of Pathology, vol. 221, no. 2, pp. 117-124, 2010.

[75] J. M. M. Levy and A. Thorburn, "Targeting autophagy during cancer therapy to improve clinical outcomes," Pharmacology and Therapeutics, vol. 131, no. 1, pp. 130-141, 2011.

[76] F. Meric-Bernstam and A. M. Gonzalez-Angulo, "Targeting the mTOR signaling network for cancer therapy," Journal of Clinical Oncology, vol. 27, no. 13, pp. 2278-2287, 2009.

[77] K. E. O'Reilly, F. Rojo, Q.-B. She et al., "mTOR inhibition induces upstream receptor tyrosine kinase signaling and activates Akt," Cancer Research, vol. 66, no. 3, pp. 1500-1508, 2006.

[78] K. Yu, C. Shi, L. Toral-Barza et al., "Beyond rapalog therapy: preclinical pharmacology and antitumor activity of WYE125132, an ATP-competitive and specific inhibitor of mTORC1 and mTORC2," Cancer Research, vol. 70, no. 2, pp. 621-631, 2010.

[79] M. E. Feldman, B. Apsel, A. Uotila et al., "Active-site inhibitors of mTOR target rapamycin-resistant outputs of mTORC1 and mTORC2," PLoS Biology, vol. 7, no. 2, Article ID e38, 2009.
[80] M. R. Janes, J. J. Limon, L. So et al., "Effective and selective targeting of leukemia cells using a TORC1/2 kinase inhibitor," Nature Medicine, vol. 16, no. 2, pp. 205-213, 2010.

[81] Q.-W. Fan, C. Cheng, C. Hackett et al., "Akt and autophagy cooperate to promote survival of drug-resistant glioma," Science Signaling, vol. 3, no. 147, article ra81, 2010.

[82] M. P. Ghadimi, G. Lopez, K. E. Torres, R. Belousov, E. D. Young et al., "Targeting the PI3K/mTOR axis, alone and in combination with autophagy blockade, for the treatment of malignant peripheral nerve sheath tumors," Molecular Cancer Therapeutics, vol. 11, pp. 1758-1769, 2012.

[83] M. Selvakumaran, R. K. Amaravadi, I. A. Vasilevskaya, and P. J. O'Dwyer, "Autophagy inhibition sensitizes colon cancer cells to antiangiogenic and cytotoxic therapy," Clinical Cancer Research, vol. 19, no. 11, pp. 2995-3007, 2013.

[84] L. Vucicevic, M. Misirkic, K. Janjetovic et al., "Compound C induces protective autophagy in cancer cells through AMPK inhibition-independent blockade of Akt/mTOR pathway," Autophagy, vol. 7, no. 1, pp. 40-50, 2011.

[85] F. Lamoureux and A. Zoubeidi, "Dual inhibition of autophagy and the AKT pathway in prostate cancer," Autophagy, vol. 9, no. 7, 2013.

[86] M. Donadelli, I. Dando, T. Zaniboni et al., "Gemcitabine/cannabinoid combination triggers autophagy in pancreatic cancer cells through a ROS-mediated mechanism," Cell Death and Disease, vol. 2, no. 4, article 152, 2011.

[87] Y. Tang, H. A. Hamed, N. Cruickshanks, P. B. Fisher, S. Grant, and P. Dent, "Obatoclax and lapatinib interact to induce toxic autophagy through NOXA," Molecular Pharmacology, vol. 81, no. 4, pp. 527-540, 2012.

[88] L. Deng, Y. Lei, R. Liu, J. Li, K. Yuan et al., "Pyrvinium targets autophagy addiction to promote cancer cell death," Cell Death and Disease, vol. 4, Article ID e614, 2013.

[89] J. Huang, K. Liu, Y. Yu et al., "Targeting HMGB1-mediated autophagy as a novel therapeutic strategy for osteosarcoma," Autophagy, vol. 8, no. 2, 2012.

[90] C. Peracchio, O. Alabiso, G. Valente, and C. Isidoro, "Involvement of autophagy in ovarian cancer: a working hypothesis," Journal of Ovarian Research, vol. 5, article 22, 2012.

[91] H.-Y. Chen and E. White, "Role of autophagy in cancer prevention," Cancer Prevention Research, vol. 4, no. 7, pp. 973983, 2011.

[92] R. K. Amaravadi, D. Yu, J. J. Lum et al., "Autophagy inhibition enhances therapy-induced apoptosis in a Myc-induced model of lymphoma," Journal of Clinical Investigation, vol. 117, no. 2, pp. 326-336, 2007.

[93] T. Munster, J. P. Gibbs, D. Shen et al., "Hydroxychloroquine concentration-response relationships in patients with rheumatoid arthritis," Arthritis and Rheumatism, vol. 46, no. 6, pp. 1460-1469, 2002.

[94] R. K. Amaravadi, J. Lippincott-Schwartz, X.-M. Yin et al., "Principles and current strategies for targeting autophagy for cancer treatment," Clinical Cancer Research, vol. 17, no. 4, pp. 654-666, 2011.

[95] K. T. Flaherty, J. R. Infante, A. Daud, R. Gonzalez, R. F. Kefford et al., "Combined BRAF and MEK inhibition in melanoma with BRAF V600 mutations," The New England Journal of Medicine, vol. 367, pp. 1694-1703, 2012.

[96] A. Broniscer, S. D. Baker, C. Wetmore et al., "Phase I trial, pharmacokinetics, and pharmacodynamics of vandetanib and dasatinib in children with newly diagnosed diffuse intrinsic pontine 
glioma," Clinical Cancer Research, vol. 19, no. 11, pp. 3050-3058, 2013.

[97] V. R. Recinos, B. M. Tyler, K. Bekelis et al., "Combination of intracranial temozolomide with intracranial carmustine improves survival when compared with either treatment alone in a rodent glioma model," Neurosurgery, vol. 66, no. 3, pp. 530$537,2010$.

[98] M. L. Bristol, S. M. Emery, P. Maycotte, A. Thorburn, S. Chakradeo et al., "Autophagy inhibition for chemosensitization and radiosensitization in cancer: do the preclinical data support this therapeutic strategy?" Journal of Pharmacology and Experimental Therapeutics, vol. 344, pp. 544-552, 2013. 


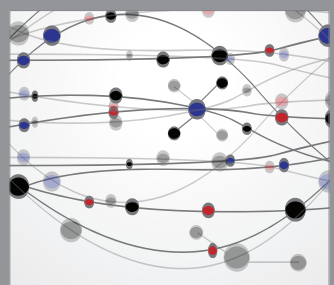

The Scientific World Journal
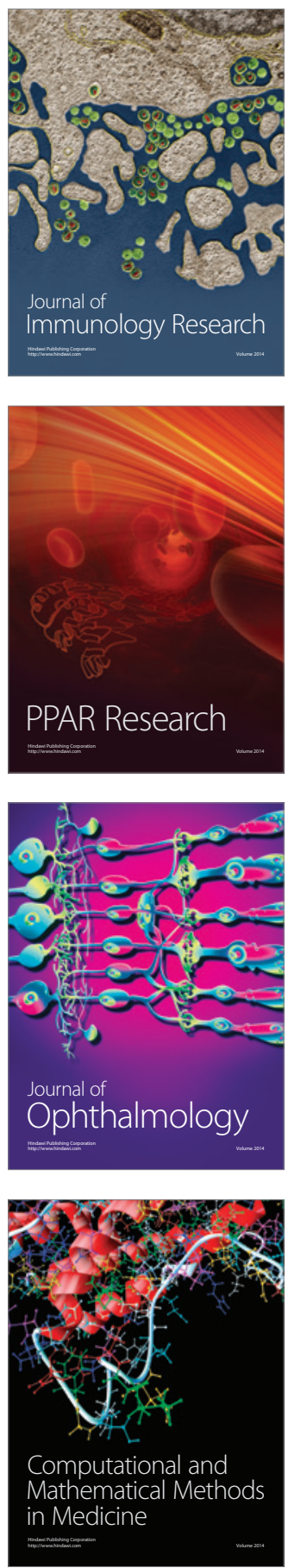

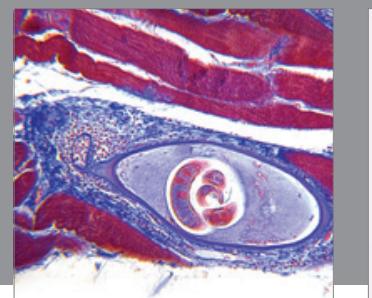

Gastroenterology

Research and Practice
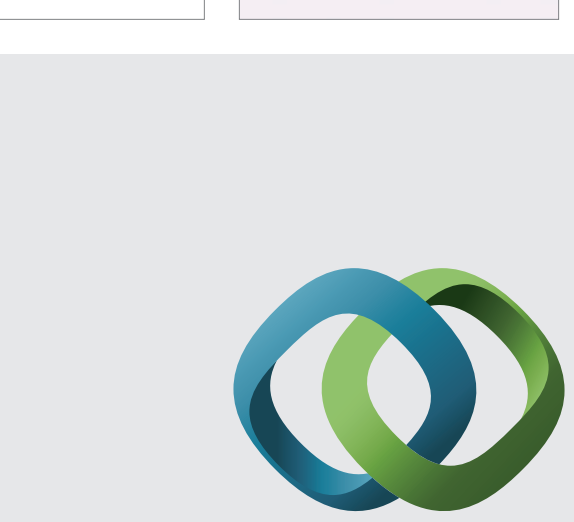

\section{Hindawi}

Submit your manuscripts at

http://www.hindawi.com
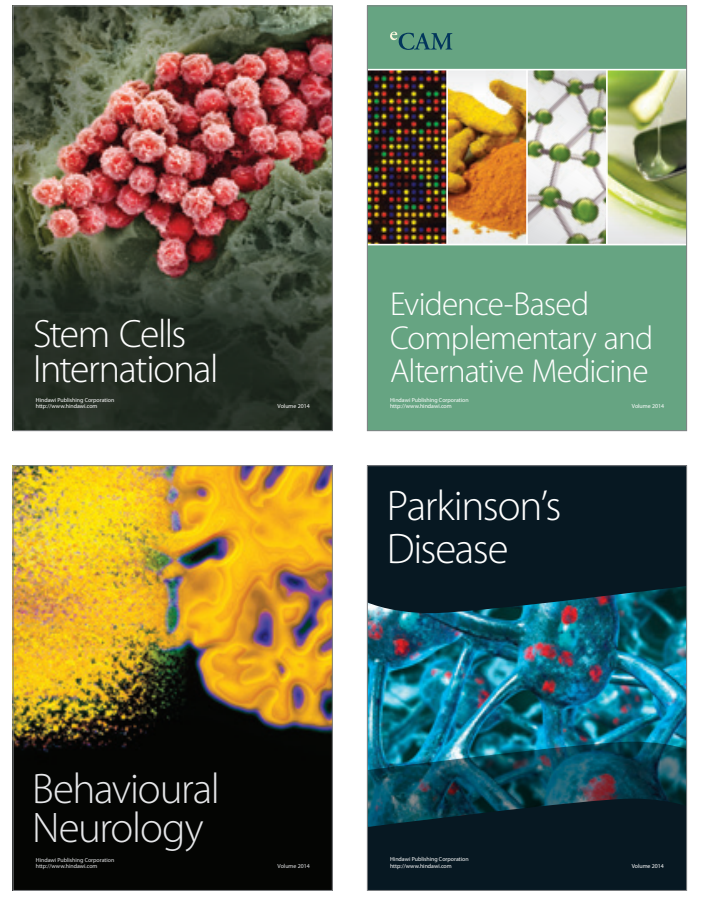
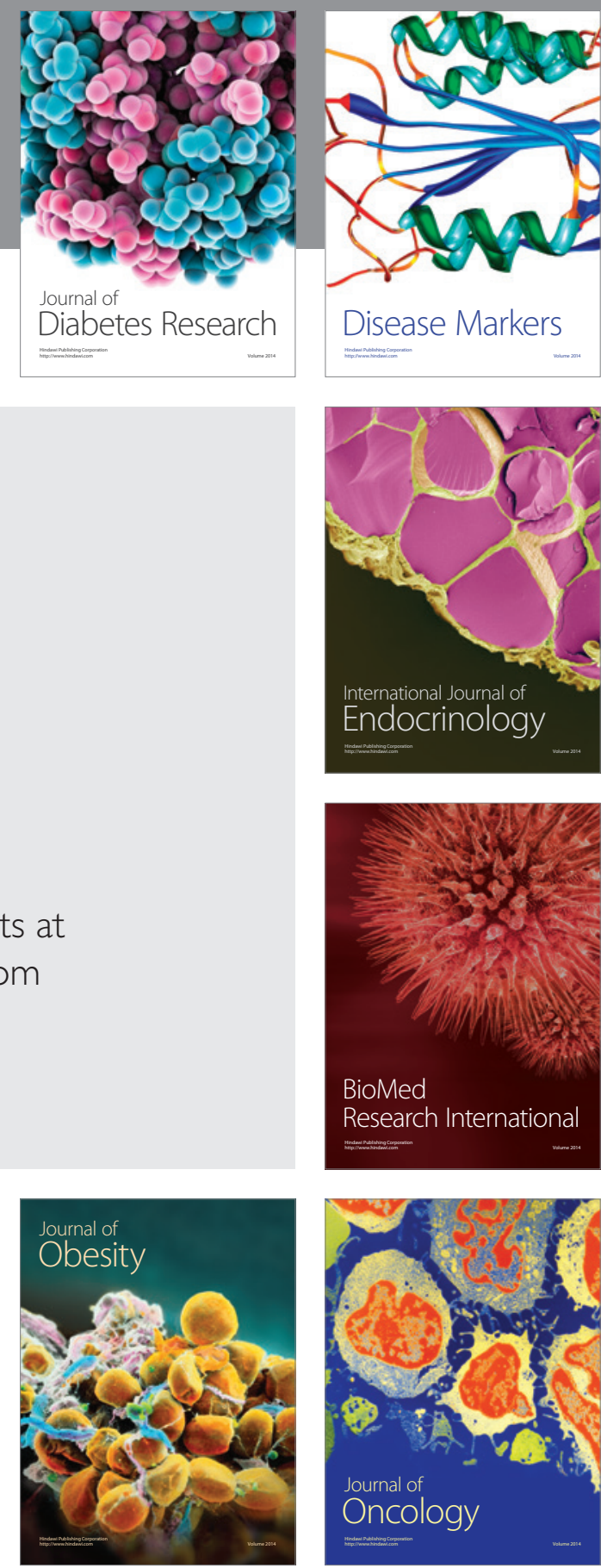

Disease Markers
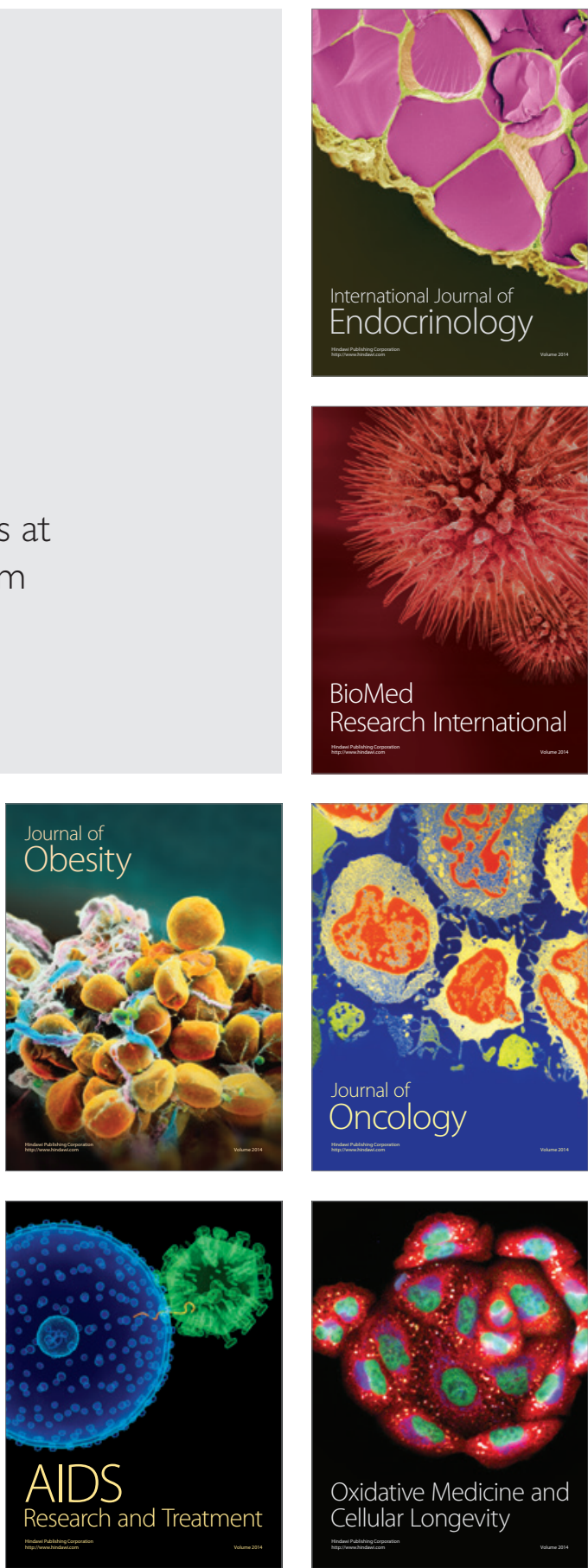